\title{
Persisting Effects of Ayahuasca on Empathy, Creative Thinking, Decentering, Personality, and Well-Being
}

\author{
Maggie K. Kiraga ${ }^{1+}$, Natasha L. Mason ${ }^{1 \dagger}$, Malin V. Uthaug ${ }^{1}$, Kim I.M. van Oorsouw ${ }^{2}$, \\ Stefan W. Toennes ${ }^{3}$, Johannes G. Ramaekers ${ }^{1}$ and Kim P. C. Kuypers ${ }^{1 *}$ \\ ${ }^{1}$ Department of Neuropsychology and Psychopharmacology, Faculty of Psychology and Neuroscience, Maastricht University, \\ Maastricht, Netherlands, ${ }^{2}$ Department of Clinical Sciences, Faculty of Psychology and Neuroscience, Maastricht University, \\ Maastricht, Netherlands, ${ }^{3} / n s t i t u t e$ of Legal Medicine, University of Frankfurt, Frankfurt, Germany
}

\section{OPEN ACCESS}

Edited by: Célia Cabral,

University of Coimbra, Portugal

Reviewed by:

Joanna Rymaszewska, Wroclaw Medical University, Poland

Sérgio Arthuro Mota-Rolim, Federal University of Rio Grande do

Norte, Brazil

${ }^{*}$ Correspondence:

Kim P. C. Kuypers

k.kuypers@maastrichtuniversity.nl

${ }^{+}$These authors have contributed equally to this work and share first authorship

Specialty section: This article was submitted to Ethnopharmacology,

a section of the journal

Frontiers in Pharmacology

Received: 07 June 2021 Accepted: 20 September 2021 Published: 01 October 2021

Citation:

Kiraga MK, Mason NL, Uthaug MV, van Oorsouw KIM, Toennes SW, Ramaekers JG and Kuypers KPC (2021) Persisting Effects of Ayahuasca on Empathy, Creative Thinking, Decentering, Personality, and Well-

Being.

Front. Pharmacol. 12:721537. doi: 10.3389/fphar.2021.721537
Background: Naturalistic and placebo-controlled studies have suggested that ayahuasca, a traditional Amazonian beverage, could be helpful in the treatment of psychopathologies like depression and anxiety disorders by changing otherwise disturbed cognitive and emotional processes. To better understand its full therapeutic potential, one way is to study the effects on processes like flexible thinking, empathy, and well-being, which are normally compromised in stress-related psychopathologies.

Materials and Methods: Volunteers attending ayahuasca ceremonies were asked to complete a test battery at three separate occasions: baseline, the morning after, and 1 week after the ceremony. We included the constructs of creative thinking (measured by Picture Concept Test), empathy (Multifaceted Empathy Test), satisfaction with life (Satisfaction with Life Scale), decentering (Experiences Questionnaire), and personality (Big Five Inventory) into the test battery. Additionally, the psychedelic experience was quantified with the Persisting Effects Questionnaire, the Ego Dissolution Scale, and Visual Analogue Scales.

Results: In total, 43 attendees (males $=22$; females $=21$ ) completed parts of the baseline assessment, 20 (males = 12; females $=8$ ) completed assessments in the morning after the ceremony, and 19 (males = 14; females = 5) completed assessments at the 1 -week followup. At one and 7 days post-ceremony, cognitive empathy, satisfaction with life, and decentering increased, while divergent thinking (Fluency corrected for Originality) decreased, when compared to baseline. Implicit emotional empathy increased at 1week follow-up, whereas ratings of the trait neuroticism decreased.

Conclusion: The study suggests that a single ingestion of ayahuasca in a social setting is associated with enhancement of subjective well-being, an enhanced ability to take an objective and non-judging stance towards the self (decentering), and the ability to correctly recognize emotions in others, compared to baseline, lasting up to 1 week post-ceremony. To understand the therapeutic potential related to these effects, further research with clinical populations is needed in which these effects can be assessed, including its link with 
therapeutic outcomes. Together, this will increase our understanding of the effectiveness and breadth of future therapeutic options.

Keywords: ayahuasca ceremony, persisting effects, empathy, creativity, well-being, decentering

\section{INTRODUCTION}

Ayahuasca is a psychoactive decoction with a reported history of use for magical, ritual, and medicinal purposes by indigenous groups of the Amazon (Schultes 1986; Schmid 2012; Frecska et al., 2016). In addition to traditional historical practices, there has been an increase in the availability of the brew to non-Amazonian populations (Tupper 2008), with people reportedly using the substance to seek insights, personal growth, emotional healing, connection with nature, out of curiosity (Winkelman 2005; Uthaug et al., 2021).

Ayahuasca is made from the stalk of the vine Banisteriopsis caapi, a source of monoamine oxidase inhibitors (MAOIs), and the leaves of the Psychotria viridis shrub, a source of N,Ndimethyltryptamine (DMT; Palhano-Fontes et al., 2015). The combination of MAOIs and DMT is required to produce the psychedelic effects (Riba et al., 2003), including shifts in cognition, emotional lability, and visionary experiences (Shanon 2002).

Studies have shown that ayahuasca could be helpful in the treatment of psychopathologies (Barbosa et al., 2005; PalhanoFontes et al., 2021; Sarris et al., 2021). To get a better understanding of ayahuasca's full potential, one way is to study its effects on mental and cognitive processes that are generally compromised in stress-related psychopathologies, like flexible thinking, empathy, metacognitive awareness, and wellbeing (Tull and Roemer, 2007; Aldao and Nolen-Hoeksema, 2010; Parlar et al., 2014; Morrison et al., 2016; Mason et al., 2019; Mason and Kuypers 2021). Previously, it was demonstrated that divergent thinking (DT) of attendees of ayahuasca ceremonies was augmented during the altered state of consciousness compared to their baseline performance, while convergent thinking (CT) was decreased (Kuypers et al., 2016). Days to months after the self-administration of ayahuasca, individuals displayed enhanced flexible (divergent) and convergent thinking (Frecska et al., 2012; Uthaug et al., 2018; Uthaug et al., 2019). Evidence to date also points to the beneficial effects of the brew on self-reported levels of life satisfaction (Uthaug et al., 2018) and depressive symptoms (de Lima Osório et al., 2011; Palhano-Fontes et al., 2019; Sanches et al., 2016; van Oorsouw et al., 2021). Studies directly assessing ayahuasca's effects on emotion regulation showed sub-acute improvements in emotional non-acceptance, emotional interference, and lack of control (Domínguez-Clavé et al., 2019) and lower scores on emotional dysregulation compared to the baseline that were sustained over the 1 year follow-up period (Bouso et al., 2012). Increments in implicit empathy (often referred to as "arousal") were shown with attendees of ayahuasca group ceremonies who received ayahuasca vs. those who received placebo (Uthaug et al., 2021). Additionally, ingestion of ayahuasca was found to be beneficial for mindfulness-related capacities (Soler et al., 2016), levels of assertiveness and joy (Barbosa et al., 2005), anxiety reduction, optimism, and selfconfidence (Da Silveira et al., 2005).

Despite the promising findings and the growing evidence suggesting a psychotherapeutic potential of the Amazonian decoction, there is still much knowledge to be gained about cognitive and psychological processes affected by ayahuasca, and the longevity of these effects. A naturalistic, observational study using a comprehensive test battery repeated over 1 week was set up with attendees of ayahuasca ceremonies to reproduce some of the well-known mood- and mindfulness-related benefits and expand the sparse findings on effects on empathy and personality. By administering the test battery on three separate occasions (baseline, the morning after, and 1 week after the ceremony), we sought to distinguish between the direct (subacute) and indirect (persisting) effects of the brew on a range of measures, including flexible thinking, empathy, and satisfaction with life. Based on the existing body of literature, we hypothesized that -during post-ceremonial measurements-participants would have greater creative and empathic abilities and higher ratings of life satisfaction and decentering, the ability to observe one's thoughts and feelings in a detached manner (Soler et al., 2014). Additionally, given the reports on psychedelic-induced changes in personality traits (Bouso et al., 2012; Bouso et al., 2015; Nour et al., 2017; Johnstad 2021) and its understudied status in the context of ayahuasca ceremonies, a personality assessment was included. Our hypotheses were in line with the novel research suggesting psychedelics-induced increases in ratings of openness (Nour et al., 2017; Johnstad 2021) and decreases in neuroticism (Erritzoe et al., 2018).

\section{MATERIALS AND METHODS}

\section{Participants}

Participants were volunteers attending ayahuasca retreats in the Netherlands, stemming from across four different locations, between 2017 and 2019. Attendees of those ceremonies were either invited to participate in the study on site, or contacted the researchers by email after hearing about the study through the retreat organizers. To participate in the study, volunteers had to be a minimum of 18 years old and proficient in English. Participants completed the test battery three times: at baseline, within $24 \mathrm{~h}$ after (hereafter referred to as sub-acute), and 7 days after the ayahuasca ceremony (hereafter referred to as follow-up). After being informed about the study and giving their consent, participants completed the baseline assessment in the week before they took part in an ayahuasca ceremony either online, or on-site. The next day, participants completed the sub-acute measurements on-site with the researcher. Seven days later, they received the final follow-up measurement online. The 
total amount of ayahuasca taken by each participant was recorded, and a sample of the ayahuasca was taken to determine the concentrations of alkaloids afterwards.

The study was conducted in accordance with the Declaration of Helsinki and subsequent amendments concerning research in humans and was approved by the Ethics Review Committee of Psychology and Neuroscience and Maastricht University (ERCPN-175-03-2017). Participation was voluntary and no incentives to participate were provided. All volunteers gave their written informed consent to participate. The research team was not involved in the screening, preparation, organization, administration, and supervision of the ayahuasca ceremonies that were visited.

\section{Study Procedure \\ Ayahuasca Ceremonies}

The neoshamanic ceremony facilitators conducted personal intakes prior to participation in the ceremonies. These included screening for the individual's physical and mental fitness to participate in the ceremony and the run through the preparatory instructions (e.g., to abstain from medications). Facilitators were not clinically trained to screen for health or mental disorders.

The general setting and organization of the ceremonies was similar throughout all of the retreats. Participants stayed in a large house together, hosted by at least two or more facilitators. Before ayahuasca ingestion, participants were acquainted with one another and were invited to take part in an "opening circle," during which each participant was given the opportunity to share with the rest of the group any personal details that they felt comfortable with. The goal was to: 1) help the group get to know each other; 2) clarify motivations for the participation in the ceremony; 3) and discuss desired outcomes of the experience. Participants ingested ayahuasca in the evening hours, and after ingestion, participants generally stayed in one room lying on a mattress or floor mat with a blanket, pillow, bucket, bottle of water, and tissue box to the side. In the room, lights were dimmed, and herbs and tobacco were burned. The day following the ingestion, participants came back together to discuss their experience with each other and the facilitators.

That said, the ceremonies also differed regarding happenings before, during, and after ayahuasca intake. Specifically, depending on the organizer, the type of opening circle differed, in that organizers invested different amounts of time in discussing why individuals were present, what they expected, and also included activities for the attendees to get to know each other, like dancing, personal sharing, and games. During the ayahuasca ceremony, the type of music being played and the availability of musical instruments could differ. Some facilitators sung healing chants (icaros) during the ceremonies. Additionally, the retreats were of various lengths, with a minimum of 2 days (and one night of ingesting ayahuasca), and a maximum of 4 days (and two nights of drinking ayahuasca). Importantly, participants always completed their baseline measurement before they ingested ayahuasca, and their sub-acute measurement the day after their first ayahuasca ingestion. Generally, it has been shown that psychotropic effects of ayahuasca start between 30 and $60 \mathrm{~min}$ post-administration, reaching maximum intensity between 60 and $120 \mathrm{~min}$, and can last up to $4 \mathrm{~h}$ after administration, although the exact time-window of the acute effects can vary strongly, depending on the amount taken and participant's characteristics (Riba et al., 2001).

\section{Ayahuasca Sample}

In total, four ayahuasca samples were obtained, one from each ceremony site. The alkaloid concentrations of the ayahuasca preparations were determined after dilution using highperformance liquid chromatography-electrospray ionizationtime-of-flight mass spectrometry (LC-MS) which was calibrated with pure reference substances of $\mathrm{N}$, N-dimethyltryptamine (DMT; Cerilliant, Round Rock TX, US), harmine, and harmaline (Aldrich Chemistry, St. Louis MO, US)

\section{Assessments}

The assessments included a demographic section, the multifaceted empathy test (MET), the picture concept test (PCT), and six questionnaires: the Satisfaction with Life scale (SWLS), the Big Five inventory (BFI), the Experiences questionnaire (EQ), the Ego Dissolution Inventory (EDI), a 10 item visual analogue scale (VAS), and the Persisting Effects Questionnaire (PEQ). All the material was provided in English. Most of the measures were filled out three times, i.e., at baseline, sub-acute, and follow-up. Exceptions of this included the EDI and VAS, only filled out once, post-session, to assess the psychedelic experience in retrospect, the PEQ, which was only performed at the follow-up to assess persisting effects of the experience, and the BFI, which was only assessed at baseline and follow-up.

\section{Multifaceted Empathy Test}

The Multifaceted Empathy Test (MET) provides behavioral indices of cognitive and affective aspects of empathy (Dziobek et al., 2008). It consists of 40 photos of people in complex emotional states, both negative, and positive (50\% pictures of each valence). Cognitive empathy (CE) is evaluated based on a recognition task, in which participants had to select one word (out of four) best matching the emotional state expressed by the person in the picture. Given the complexity of depicted emotional states, the words were provided in three languages: English, Dutch, and German. The possible range of scores for CE is 0-40 (one point for each emotion recognized correctly). Emotional empathy (EE) assessed by this test can be divided into two subcategories: implicit and explicit. The former is estimated by participant's ratings of 'how aroused this picture made them feel', while the latter by ratings of "how concerned they felt for the person in the picture". Both ratings of EE are assessed on a scale from 1 to 9 . The summed and valence-specific accuracy of the correctly recognized emotions and averaged and valence-specific ratings of arousal and concern were used as dependent variables. Previous validity and reliability analysis of the MET have shown to be in the good to highly satisfactory range (Dziobek et al., 2008). 


\section{Picture Concept Test}

The picture concept test (PCT) was used to assess creativity (Kuypers et al., 2016). The PCT consists of stimuli containing between 4 and 12 color pictures shown in two or three rows. The pictures were taken from the Wechsler Preschool, Primary Scale of Intelligence, and the Wechsler Intelligence Scale for Children. Participants were instructed to find an association between one of the pictures in each row, with instructions to provide one solution only, as there is one correct answer. The total number of correct answers serves as the dependent measure of convergent thinking.

To assess divergent thinking, participants were asked to provide as many alternative associations as possible between the colored pictures. This is the regular instruction included in measures of divergent thinking, and it is used to calculate several parameters, i.e., originality, fluency, and the ratio of both, which reflects the quality of divergent thinking as originality is corrected for quantity. Fluency is defined as the number of alternative associations. Originality is calculated by evaluating the originality of the alternative association relative to those provided by all other participants in a session. Alternative answers that were uniquely reported by a single participant received an originality score of 2 . Answers that were shared with a single participant were valued as 1 , and answers that were shared by three or more participants were rated zero. Mean originality (creativity) scores and ratio, originality scores weighed for fluency (originality/ fluency), were used as measures of divergent thinking.

At the time of each measurement, a different (parallel) version of PCT was used to avoid learning effects. Each parallel version consisted of 17 stimuli, the participant was given $30 \mathrm{~s}$ per stimulus.

\section{Satisfaction with Life Scale}

The Satisfaction With Life Scale (SWLS) has been developed to quantify the life satisfaction component of subjective well-being (Diener et al., 1985). The SWLS is five items long and includes sentences like In most ways, my life is close to my ideal; So far I have gotten the important things I want in life. The participants were asked to rate every item on a seven-point Likert scale, ranging from 1 (Strongly disagree) to 7 (Strongly agree). The total score ranges from 5 to 35 and is obtained by summarizing the ratings given per each item. Higher scores indicate greater life satisfaction, with a score of 20 representing a neutral point on the scale. The original scale has high internal consistency (coefficient alpha ranging from 0.79 to 0.89 ) and good test-retest correlations (up to 0.84 with one-month interval; Diener et al., 1985).

\section{Big Five Inventory}

The 44-item English version of the Big Five Inventory (BFI), developed by John et al. (1991) was used to measure personality traits. The scale was constructed to allow efficient and flexible assessment of the five personality dimensions: extraversion, agreeableness, conscientiousness, neuroticism, and openness to experience. Participants rated each BFI item on a 5-point scale ranging from 1 (disagree strongly) to 5 (agree strongly); Scale scores were computed by summing items associated with each trait. The five dimensions were measured by a different number of items. Overall, the scores range between 8 and 50 for each personality trait. The BFI scales have shown substantial internal consistency, retest reliability, and clear factor structure (John and Srivastava, 1999).

\section{Experiences Questionnaire-Decentering}

The Experiences Questionnaire (EQ) is a self-report instrument that originally assessed decentering and rumination and was validated by Fresco and colleagues (2007). The 11-item EQDecentering (EQ-D) subscale was developed to quantify the ability to observe one's thoughts and feelings in a detached manner. Participants rated items on a 5-point Likert-type scale ( $1=$ never to $5=$ all the time $)$, assessing three facets: the ability to distinguish one's self from one's thoughts, the ability to not habitually react to one's negative experiences, and the capacity for self-compassion (Fresco et al., 2007). The total score was calculated by calculating the mean of all 11 items and ranges from 1 to 5 . The psychometric characteristics of the original scale have shown a robust structure for the decentering factor, with high internal reliability (Fresco et al., 2007).

\section{Ego Dissolution Inventory}

The Ego Dissolution Inventory (EDI) is an eight-item self-report scale that assesses the participant's experience of ego dissolution (Nour et al., 2016). In the present study, the original, English version was used to acquire a better understanding of the experiences the participants had about ego dissolution during the ayahuasca ceremony. For example "I experienced a dissolution of my "self or ego" and "I felt at one with the Universe". The participants answered the scale with endpoints of either 0 (No, not more than usual) or 100 (Yes, I experienced this completely/ entirely). The EDI was scored by calculating the mean of all items, with a higher total score indicating a stronger experience of ego dissolution. The scale has been shown to have excellent internal consistency (Nour et al., 2016).

\section{Visual Analogue Scale}

The morning after the ceremony, participants were asked to retrospectively rate the intensity of various aspects of the acute ayahuasca experience using 10 visual analogue scales (VASs). These included $10 \mathrm{~cm}$ horizontal lines, with a bottom anchor of not more than usual and a top anchor of much more than usual. Example items were: These items have previously been shown to be sensitive to the acute effects of psychedelics (Carhart-Harris et al., 2012; Mason et al., 2019).

\section{Persisting Effects Questionnaire}

The Persisting Effects Questionnaire (PEQ) is a 143-item long scale aiming to assess changes in attitudes, moods, behavior, and spiritual experience (Griffiths et al., 2006). Prior research found that PEQ is sensitive to the prolonged effects of psychedelics, occurring even a 1 year after the ingestion (Schmid and Liechti 2018). Due to time constraints, the current study used a shortened version of the scale (90 items), including five out of six main categories. Specifically, the following categories were tested: attitudes about life [Number of items $(\mathrm{N})=26$; attitudes about self $(\mathrm{N}=22)$; mood changes $(\mathrm{N}=18)$; relationships $(\mathrm{N}$ $=18)$; and behavioral changes $(\mathrm{N}=2)$. The 86 items of these five 
categories were rated on a 6-point scale (ranging from $0=$ none to 5 = extreme). The scores of the resulting 10 scales (positive and negative scales for each of five categories) were assessed by calculating mean (SE) separately for each category.

The questionnaire included four additional questions (see Griffiths et al., 2006 for details): 1) How personally meaningful was the experience? (rated from 1 to 8 , with $1=$ no more than routine, and 8 = the single most meaningful experience of my life); 2) Indicate the degree to which the experience was spiritually significant to you? (rated from 1 to 8 , using the same encoding as the first question); 3) How psychologically challenging were the most psychologically challenging portions of the experiences? (rated from 1 to 8 , using the same encoding as the first question); 4) How personally psychologically insightful to you were the experiences? (rated from 1 to 8 , using the same encoding as the first question).

\section{Statistical Analyses}

Data analyses and visualizations were performed using the Matplotlib (version 3.2.2), Statsmodels (version 0.11.1), and Pingouin (version 0.3.8) libraries for Python3. A separate multi-linear regression model using the ordinary least square method (OLS) was fit for each outcome variable. The model included Session encoded as a dummy independent variable of three levels: baseline, the morning after ceremony, and 7 days after the ceremony. Subsequently, if a main effect of Session was found, separate contrasts were performed between baseline, subacute, and follow-up sessions. For the MET, if a main effect of Session was found on emotional or cognitive empathy, two further analyses were done, separating valence-specific (positive or negative emotion) responses.

Ayahuasca experience ratings were analyzed separately using a one-sample t-test comparing the scores on each VAS after ceremony to a zero distribution since previous studies have shown that placebo scores are low, not rising above a 0 in a scale from 0 to 100 (Valle et al., 2016).

Hypothesis-driven correlational analysis was run to try and replicate results from a previous study that showed enhancements in empathic processes were correlated with increased satisfaction with life (Mason et al., 2019). The correlations were run between variables of empathy that showed ayahuasca treatment effects, and satisfaction with life. One-sided Pearson's correlations were carried out using baseline change scores $(24 \mathrm{~h}$ after-baseline; 7 days after-baseline). For all statistical analyses, the alpha criterion level of statistical significance was set at $p \leq 0.05$ and Cohen's effect (d) size was reported in case of significant results to demonstrate the effect's magnitude with $0.2-0.5$ considered as small, $0.5-0.8$ as a medium, and $>0.8$ as large effect size (Leary, 2014).

\section{RESULTS}

\section{Participants}

A total of 64 volunteers signed the informed consent form and agreed to participate in the study. Incomplete or missing test batteries were due to time constraints and/or participant dropout.

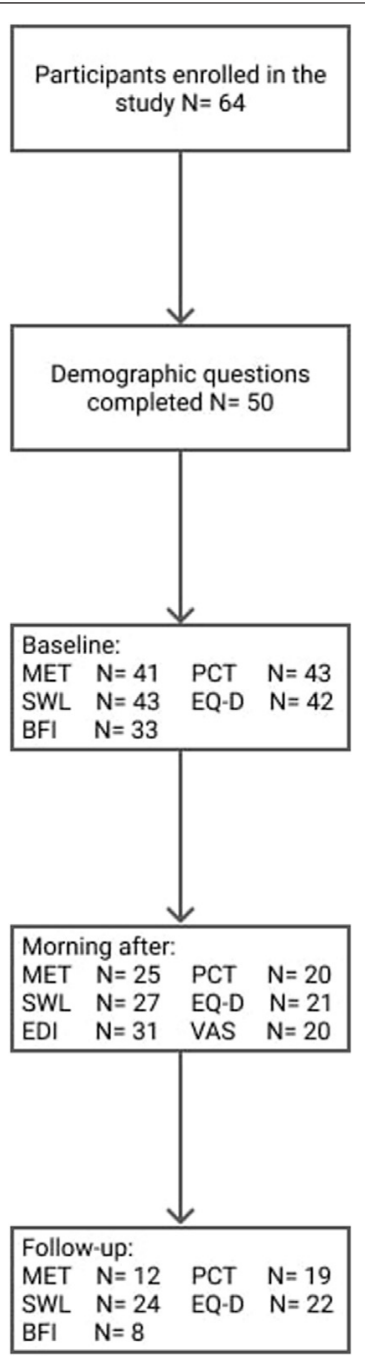

FIGURE 1 | Flow-chart depicting participants' enrollment.

More information regarding participants' enrollment and completion rates can be found in Figure 1.

The majority of the participants (55\%) were males, $42 \%$ were females, and $3 \%$ chose not to answer the question. We did not test for possible sex differences at any of the study time points, as it would divide the sample sizes approximately in half, which would result in too small subgroups to conduct meaningful statistics on. The mean $( \pm$ SD) age of the entire group was $39 \pm 11.3$ years. Most participants were from Europe (78\%), while the rest were from North America (10\%), the Middle East (4.7\%), or undisclosed (7.3\%). The majority of the group (61\%) completed an academic level of education. About one-fourth (23.4\%) of the participants had used ayahuasca before, and all of them did so during a group retreat. Furthermore, 52\% of the participants had previously used psychedelics other than ayahuasca, e.g., psilocybin, LSD, and DMT. When asked about the motivations for attending the ceremony, participants often indicated "to understand myself" (67\%), and "to resolve problems" (59\%). Next to that, "curiosity" $(37.5 \%)$ and "other" (31\%) motives were mentioned. 
TABLE 1 | Estimated average total dose per site, based on alkaloid concentrations and reported amounts of the brew that participants have taken.

\begin{tabular}{|c|c|c|c|c|}
\hline Sample & $\mathrm{N}$ from this location & DMT (mg) & Harmine (mg) & Harmaline (mg) \\
\hline Location 1 & 15 & 65.88 & 251.93 & 26.25 \\
\hline Location 2 & 14 & 69.7 & 91.00 & 167.30 \\
\hline Location 3 & 8 & 19.20 & 21.60 & 4.20 \\
\hline Location 4 & 3 & 75.00 & 143.80 & 41.60 \\
\hline
\end{tabular}
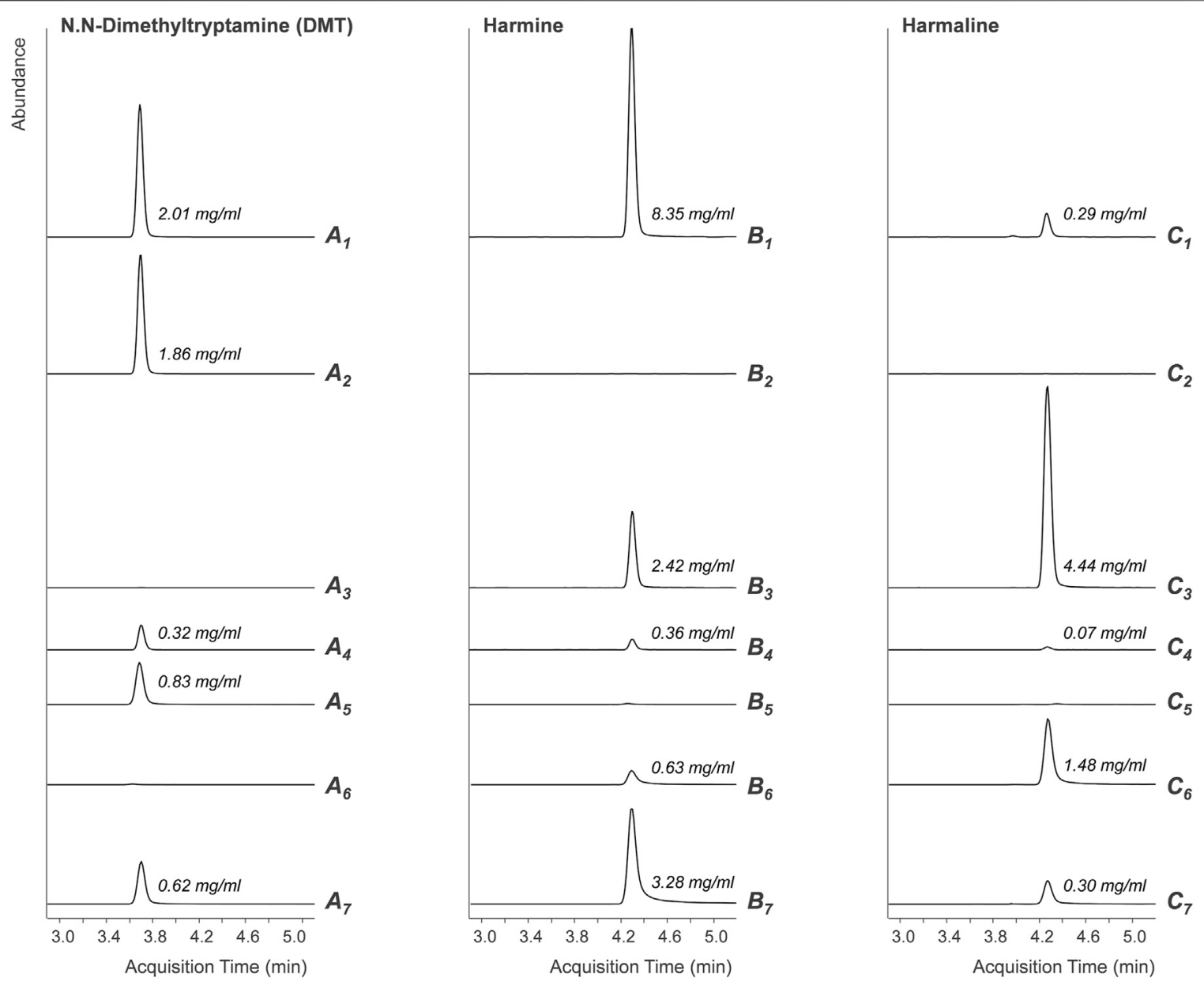

FIGURE 2 | Extracted ion chromatograms of LC-MS analyses of the ayahuasca's active ingredients DMT (A), harmine (B) and harmaline (C) in the preparations used in Location 1 (index 1), Location 2 (consisting of Mimosa hostilis, index 2, and Peganum harmala, index 3), Location 3 (index 4 ) and Location 4 (consisting of Mimosa hostilis, index 5 , Peganum harmala, index 6 , and a preparation of Banisteriopsis muricata, index 7 ). The abundances of the analytical signals are equally scaled for each analyte and the concentrations in the brews are annotated.

\section{Ayahuasca Sample}

Table 1 shows the results of the analysis of the ayahuasca samples per organization, the concentrations of which vastly differed between locations; Figure $\mathbf{2}$ shows the chromatograms of the ayahuasca samples. Based on participants' reports on the amount of consumed ayahuasca, and metabolites' analysis afterwards it was calculated that the average $( \pm S D)$ amount of DMT, harmine, and harmaline was respectively 57.44 (25.77) $\mathrm{mg}$, 127.08 (97.12), and 59.84 (73.27) $\mathrm{mg}$.
Multifaceted Empathy Test

\section{Cognitive Empathy}

Overall 41 (at baseline), 25 (at the morning after the ceremony), and 12 (at 1 week after the ceremony) participants completed all the parts of MET and were included into analyses. The OLS multi-linear regression revealed a significant main effect of Session $\left(\mathrm{F}_{2,75}=12.77 ; p<0.001\right)$ on CE. Compared to baseline, participants correctly identified more emotions the morning after the ayahuasca ceremony $(p<0.001 ; d=0.93)$, and 1 week after the ceremony ( $p=0.01 ; d=0.79$; Table 2$)$. 
TABLE 2 | Summary of contrast analyses of the dependent measures.

\begin{tabular}{|c|c|c|c|c|c|c|}
\hline Variable & Session & $\mathbf{N}$ & Mean & SE & $P$ & $d$ \\
\hline \multirow[t]{3}{*}{ Total Cognitive Empathy } & Baseline & 41 & 16.7 & 0.88 & & \\
\hline & Sub-acute & 25 & 22.67 & 1.42 & $<0.001^{*}$ & 0.93 \\
\hline & Follow-up & 12 & 21.49 & 1.84 & $0.01^{*}$ & 0.79 \\
\hline \multirow[t]{3}{*}{ Positive Cognitive Empathy } & Baseline & 41 & 8.17 & 0.51 & & \\
\hline & Sub-acute & 25 & 11.12 & 0.83 & $<0.001^{*}$ & 0.79 \\
\hline & Follow-up & 12 & 11 & 1.1 & $0.01^{\star}$ & 0.8 \\
\hline \multirow[t]{3}{*}{ Negative Cognitive Empathy } & Baseline & 41 & 8.54 & 0.48 & & \\
\hline & Sub-acute & 25 & 11.55 & 0.78 & $<0.001^{*}$ & 0.85 \\
\hline & Follow-up & 12 & 10.49 & 1.0 & 0.056 & 0.59 \\
\hline \multirow[t]{3}{*}{ Average Implicit Emotional Empathy } & Baseline & 41 & 4.92 & 0.21 & & \\
\hline & Sub-acute & 25 & 5.3 & 0.34 & 0.27 & 0.25 \\
\hline & Follow-up & 12 & 5.8 & 0.44 & $0.047^{*}$ & 0.62 \\
\hline \multirow[t]{3}{*}{ Positive Implicit Emotional Empathy } & Baseline & 41 & 4.52 & 0.28 & & \\
\hline & Sub-acute & 25 & 4.71 & 0.46 & 0.68 & 0.1 \\
\hline & Follow-up & 12 & 6.05 & 0.6 & $0.01^{\star}$ & 0.78 \\
\hline \multirow[t]{3}{*}{ Negative Implicit Emotional Empathy } & Baseline & 41 & 5.32 & 0.25 & & \\
\hline & Sub-acute & 25 & 5.89 & 0.4 & 0.15 & 0.32 \\
\hline & Follow-up & 12 & 5.58 & 0.5 & 0.62 & 0.16 \\
\hline \multirow[t]{3}{*}{ Average Explicit Emotional Empathy } & Baseline & 41 & 4.2 & 0.18 & & \\
\hline & Sub-acute & 25 & 4.5 & 0.29 & 0.3 & 0.23 \\
\hline & Follow-up & 12 & 4.37 & 0.38 & 0.65 & 0.14 \\
\hline \multirow[t]{3}{*}{ Convergent Thinking } & Baseline & 43 & 10.14 & 0.42 & & \\
\hline & Sub-acute & 20 & 10.55 & 0.75 & 0.58 & 0.13 \\
\hline & Follow-up & 19 & 12.95 & 0.76 & $<0.001^{\star}$ & 0.83 \\
\hline \multirow[t]{3}{*}{ Originality } & Baseline & 43 & 5.35 & 0.72 & & \\
\hline & Sub-acute & 20 & 7.9 & 1.27 & 0.05 & 0.52 \\
\hline & Follow-up & 19 & 3.37 & 1.3 & 0.13 & 0.41 \\
\hline \multirow[t]{3}{*}{ Fluency } & Baseline & 43 & 4.93 & 0.65 & & \\
\hline & Sub-acute & 20 & 7.5 & 1.14 & 0.03 & 0.55 \\
\hline & Follow-up & 19 & 5.42 & 0.49 & 0.68 & 0.16 \\
\hline \multirow[t]{3}{*}{ Ratio (Originality/Fluency) } & Baseline & 43 & 1.23 & 0.05 & & \\
\hline & Sub-acute & 20 & 1.04 & 0.09 & $0.04^{\star}$ & 0.5 \\
\hline & Follow-up & 19 & 0.68 & 0.1 & $<0.001^{\star}$ & 1.27 \\
\hline \multirow[t]{3}{*}{ Satisfaction with Life Scale } & Baseline & 43 & 19.1 & 0.87 & & \\
\hline & Sub-acute & 27 & 22.3 & 1.39 & $<0.001^{\star}$ & 1.0 \\
\hline & Follow-up & 24 & 24.9 & 1.45 & $<0.001^{\star}$ & 1.76 \\
\hline \multirow[t]{3}{*}{ Decentering } & Baseline & 42 & 3.18 & 0.07 & & \\
\hline & Sub-acute & 21 & 3.76 & 0.13 & $<0.001^{*}$ & 1.0 \\
\hline & Follow-up & 22 & 4.12 & 0.13 & $<0.001^{*}$ & 1.76 \\
\hline \multirow[t]{2}{*}{ Personality: Neuroticism } & Baseline & 33 & 24.58 & 6.34 & & \\
\hline & Follow-up & 8 & 19.5 & 3.66 & $0.037^{\star}$ & 0.98 \\
\hline
\end{tabular}

${ }^{*} p<0.05$

When assessing valence-specific responses, analysis revealed a significant main effect of Session on recognition of both positive $\left(\mathrm{F}_{2,75}=11.82 ; p<0.001\right)$ and negative $\left(\mathrm{F}_{2,75}=8.47, p=0.005\right)$ emotions (Table 2) indicating that the morning after the ceremony, participants correctly recognized more positive and negative emotions than during the baseline measurement $(p<$ $0.001 ; d=0.79$ and $p<0.001 ; d=0.85$, respectively). At follow-up, participants correctly recognized more positive emotions $(p=$ $0.01 ; d=0.8$ ) compared to baseline; whereas recognition of negative emotions did not differ statistically between baseline and 7-days follow-up ( $p=0.056 ; d=0.59$ ).

\section{Emotional Empathy}

The OLS multi-linear regression model revealed a significant effect of Session on Implicit EE $\left(\mathrm{F}_{2,75}=4.42 ; p=0.04\right.$; Table 2). Compared to baseline, participants reported significantly higher arousal levels during the follow-up when confronted with emotional expressions ( $p=0.047 ; d=0.62$ ). There was no significant effect of Session on implicit EE ( $p=0.266)$, when comparing baseline to sub-acute measurement. Furthermore, the one-factor, multi-linear regression model did not reveal a significant main effect of Session on the average scores of Explicit EE scores ("concern", $\mathrm{F}_{2,75}=0.572 ; p=0.452$ ).

Similar time effects were found for valence-specific responses. The analysis revealed an overall effect of Session towards positive emotions $\left(\mathrm{F}_{2,75}=5.193 ; p=0.025\right.$; Table 2$)$ and no changes in arousal levels towards negative pictures $\left(\mathrm{F}_{2,75}=0.218 ; p=0.642\right)$. Specifically, compared to baseline, participants reported significantly higher arousal levels towards positive pictures 1 week after the ceremony ( $p=0.012 ; d=0.78$ ); these effects were not present at follow-up $(p=0.679)$.

\section{Picture Concept Test}

Convergent Thinking

In total 43, 20, and 19 participants completed the first part (convergent thinking) of the PCT during the first, second, and 


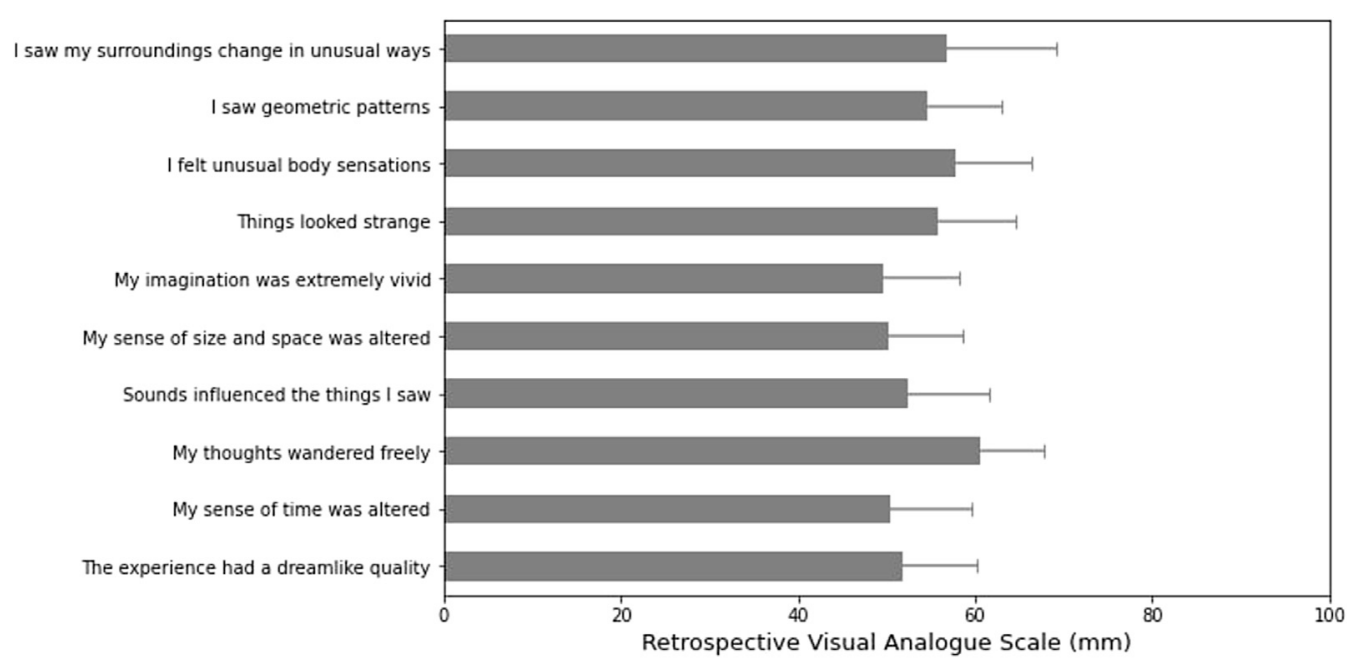

FIGURE 3 | Mean ( \pm SE) of visual analogue scale item scores on a $100 \mathrm{~mm}$ scale. Scores are retrospective of the ceremony experience.

third assessment, respectively. Analysis revealed a significant main effect of Session on convergent thinking $\left(\mathrm{F}_{2,79}=12.08\right.$; $p<0.001$; Table 2). Separate contrasts showed that the number of correct solutions non-significantly increased after the ayahuasca ceremony $(p=0.58)$, reaching statistical significance at follow-up measurement $(p<0.001 ; d=0.83)$.

\section{Divergent Thinking}

Analysis revealed no effect of Session on originality $\left(\mathrm{F}_{2,79}=0.858\right.$; $p=0.357$; Table 2), nor fluency scores $\left(\mathrm{F}_{2,79}=0.717 ; p=0.4\right)$. When the originality scores were weighted for fluency (the ratio) a significant effect of Session was found $\left(\mathrm{F}_{2,65}=30.57 ; p<0.001\right)$, with ratio, an estimator of divergent thinking's quality, being significantly lower the morning after and 1 week after the ceremony than at the baseline $(p=0.038 ; d=0.5$ and $p<$ $0.001 ; d=1.27$, respectively).

\section{Satisfaction with Life Scale}

The questionnaire was completed by 43 participants at baseline, 27 the morning after the ceremony, and 24 at the follow-up. The multi-linear regression analysis revealed a significant main effect of Session on participants' satisfaction with life ratings $\left(\mathrm{F}_{2,91}=\right.$ 17.0; $p<0.001$; Table 2). Separate contrasts indicated that, compared to baseline, satisfaction with life significantly increased the morning after $(p=0.023 ; d=0.5)$ and 1-week after the ceremony $(p<0.001 ; d=0.9)$.

\section{Experience Questionnaire-decentering}

The questionnaire was completed by 42 participants at the baseline, 21 on the morning after the ceremony, and 22 participants at the follow-up. Analysis showed a significant effect of Session on participants' rating of decentering $\left(\mathrm{F}_{2,82}=\right.$ 60.67; $p<0.001$; Table 2). Contrasts revealed a significant continuous, linear increase of participants' decentering scores the morning after $(p=<0.001 ; d=1)$ and 1 week after the ceremony (and $p<0.001 ; d=1.76$ ) compared to baseline.
TABLE 3 | Mean (SE) scores on the first part of the Persisting Effects Questionnaire.

\begin{tabular}{lcc} 
Variable & Positive mean (SE) & Negative mean (SE) \\
\hline Attitudes about life & $57.41(3.77)$ & $15.71(0.65)$ \\
Attitudes about self & $45.06(3.06)$ & $12.71(0.43)$ \\
Mood changes & $38.82(2.93)$ & $9.47(0.23)$ \\
Social effects & $33.00(3.12)$ & $11.35(0.78)$ \\
Behavior changes & $4.41(0.39)$ & $1.06(0.06)$
\end{tabular}

\section{THE PSYCHEDELIC EXPERIENCE}

\section{Ego Dissolution Inventory}

In total, 31 participants filled in the ego dissolution inventory the morning after the ceremony. The mean (SD) of the sample was 45.8 (33.7), with ratings varying between 0 (minimal reported score) and 95.6 (maximal recorded rating).

\section{Visual Analogue Scale}

Overall, 20 participants filled in the visual analogue scale the morning after the ceremony. Mean (SE) ratings on the different VAS items are shown in Figure 3. The one-sample $t$-test showed ayahuasca-induced significant increases in all VAS items $\left(t_{19}=\right.$ 5.15-7.95; $p \leq 0.000 ; d=1.63-2.51)$.

\section{Big Five Inventory}

Personality was assessed twice; before $(\mathrm{N}=33)$ and 1 week after the ceremony $(\mathrm{N}=8)$. Linear regression analysis revealed a significant effect of Session on participants' ratings of neuroticism $\left(\mathrm{F}_{1,39}=4.68 ; p=0.037 ; \mathrm{d}=0.98\right.$; Table 2$)$, with scores being significantly lower at the 1-week follow-up than at the baseline. Participants' reports did not indicate any other significant changes in the remaining personality traits openness, extraversion, agreeableness, conscientiousness) of the BFI scale. 


\section{Persisting Effects Questionnaire}

In total, 17 participants filled in the PEQ 7 days after the ceremony. Mean (SE) of the positive and negative ratings assessing attitudes, mood, social effects, and behavior, measured after ayahuasca ceremony by the PEQ are presented in Table 3.

On the question, "how personally meaningful was the experience" $2(11.8 \%)$ rated it as the single most meaningful experience of their lives, whereas $9(52.9 \%)$ and $3(17.6 \%)$, rated it as among the 5 and 10 most meaningful experiences of their lives, respectively. One participant (5.9\%) rated it as similar to the meaningful experiences that occur on average once every 5 years, one $(5.9 \%)$ stated it was similar to meaningful experiences that occur once a year, and one (5.9\%) said it was similar to experiences that occur on average once a month.

On the question, "how spiritually significant was the experience," $8(47.1 \%)$ rated it as the most spiritually significant experience of their lives, whereas $4(23.5 \%)$ and 2 $(11.8 \%)$ rated it as among the 5 and 10 most spiritual experiences of their lives, respectively. One participant (5.9\%) rated it as similar to the spiritually meaningful experiences that occur on average once every 5 years, one (5.9\%) stated it was similar to spiritually meaningful experiences that occur once a year, and one (5.9\%) stated it was similar to spiritually meaningful experiences that occur on average once a month.

In regards to how psychologically challenging the experience was, $2(11.8 \%)$ rated it as the single most difficult or challenging experience of their lives, $6(35.3 \%)$ rated it as among the five most challenging experiences of their lives, and $3(17.6 \%)$ rated it as among the top 10 of most challenging experiences of their lives, followed by $2(11.8 \%)$ stating it was similar to the challenging experiences that occur every 5 years, $2(11.8 \%)$ who said occur every once a year, and $2(11.8 \%)$ who said occur once a month.

Finally, regarding the psychologically insightfulness of the experience, $4(23.5 \%)$ stated the experience to be the single most psychological insightful experience of their lives, 5 (29.4\%), and $4(23.5 \%)$ stated among the 5 and 10 most insightful experiences, respectively. One (5.9\%) stated that the experience was similar to psychologically insightful experiences that occur on average once every 5 years, two (11.8\%) stated it was similar to experiences that occur on average once a month and one (5.9\%) stated the experience was no different from every psychologically insightful experience.

\section{Hypothesis-Driven Correlations}

Analysis showed a correlation between changes in implicit EE towards a positive stimulus, and persisting ( 7 days) changes in satisfaction with life $(\mathrm{r}=0.584, p=0.038, \mathrm{n}=10$, one-sided $)$. Namely, as changes in arousal to pictures of people in positive mood states increased, so did changes in satisfaction with life when comparing baseline to 7 days after intake.

\section{DISCUSSION}

The primary objective of the present study was to complement the existing findings on sub-acute and long-term effects of ayahuasca on flexible cognition, empathy, satisfaction with life, and personality, using a comprehensive test battery with participants attending ayahuasca ceremonies. Relative to the baseline, we observed increases with medium and large effect sizes of convergent thinking (CT), cognitive and implicit emotional empathy (IEE), satisfaction with life (SWLS), and decentering. We also found sub-acute and long-term decreases in the estimator of divergent thinking quality (ratio, defined as originality weighted for fluency). In line with our assumptions, we found decreases in the personality trait neuroticism at 1 week post-ceremony, however contrary to our hypotheses no improvements in openness were found.

The findings demonstrate post-ayahuasca ceremony increases in participants' ability to correctly recognize emotional states, for pictures depicting both positive and negative emotions. To our knowledge, this is the first study to demonstrate large, sub-acute, and long-term increases in cognitive empathy among attendees of ayahuasca ceremonies. The present findings contrast with those of previous research with psychedelics and empathogens, where emotional recognition was unaffected (Kuypers et al., 2017; Pokorny et al., 2017; Mason et al., 2019; Uthaug et al., 2021) or even impaired after the administration of LSD, psilocybin, ayahuasca, and MDMA (Bedi et al., 2010; Kometer et al., 2012; Hysek et al., 2014; Dolder et al., 2016). Regarding emotional empathy (EE), a time- and construct-specific differentiation of effects was found, with increases of implicit EE 1 week after the ceremony and no effects on explicit EE. Similarly to the study of Pokorny and colleagues (2017), the present findings show medium increases in participants' ratings of arousal (implicit EE) towards positive emotions 1 week after the ceremony. Overall, there is growing evidence supporting the claim of acute enhancements in EE after administration of psychedelics and other serotonergic compounds, like MDMA and psilocybin (Hysek et al., 2014; Schmid et al., 2014; Preller et al., 2015; Kuypers et al., 2017; Pokorny et al., 2017; Kuypers, 2018). The current study adds to this body of literature by pointing out the possible long-term enhancements of emotion recognition/ awareness, which might bring interesting therapeutic applications of psychedelics' use for stress-related psychopathologies like depression, anxiety disorders, and posttraumatic stress disorder, which are characterized by low levels of empathy (Donges et al., 2005; Chamberlain et al., 2006; Nietlisbach and Maercker 2009; Cusi et al., 2011; Palm and Follette 2011; Lee and Orsillo 2014; Parlar et al., 2014; Morrison et al., 2016). A hypothesis-driven correlation analysis indeed suggested a positive correlation between sub-acute increases in ratings of emotional empathy and 7-days increases in satisfaction with life; in line with a previous study which found the same relationship after ingestion of psilocybin in a naturalistic setting (Mason et al., 2019). Taken together, results provide limited evidence for directionality, as they demonstrate that an earlier (morning after) increase in positive empathy strongly correlates with a later ( 7 days after) increase in wellbeing. However, future research should more formally assess a causal relationship between (positive) empathy and well-being, Additionally, assessments of sleep quality could be considered in future research since sleep quality is related to both constructs, 
and ayahuasca has been shown to affect sleep parameters, although the behavioral consequences are yet to be examined (Barbanoj et al., 2008).

With regard to convergent thinking (CT), the study showed that at 1 -week post-ceremony the performance was significantly increased, which is in line with previous studies showing enhancements in CT at 1 week (Mason et al., 2019), and 1 month (Uthaug et al., 2018) post-psychedelic ceremony, but not the morning after. These findings, although promising, should be interpreted with caution as practice effects cannot be ruled out. To minimize this, parallel versions of the test were used at each assessment point, and no feedback on performance was given. Nevertheless, practice effects have been suggested when utilizing this task in a placebo-controlled, experimental study with psilocybin (Mason et al., 2021).

The current study found decrements in divergent thinking (quantified as the ratio of originality and fluency) at both postceremonial assessments. Naturalistic studies that have used this task (Picture Concept Test) have shown mixed results, with one study finding unaffected divergent thinking 1 day after an ayahuasca ceremony (Uthaug et al., 2018), and others pointing out acute (Kuypers et al., 2016) and sub-acute (Mason et al., 2019) increases in DT following respectively the ingestion of ayahuasca and psilocybin in a social setting. Recently, a placebo-controlled study assessing the effect of psilocybin on acute and persisting creative cognition found an acute decrease in deliberate, taskbased DT across creativity tasks, and a simultaneous acute increase in ratings of spontaneous creative insight (Mason et al., 2021). Conversely, 7 days later, a DT variable was found to be increased, in that individuals were able to come up with more new ideas for one of the creativity tasks. Findings suggest a time- and test-related differentiation of effects on creative thinking, which should be considered when assessing creativity in future studies (Mason et al., 2021).

Self-rated satisfaction with life (SWL) increased during the sub-acute and long-term assessment when compared to baseline. According to an interpretation of the SWL scores provided by Diener et al. (1985), the participants in the current study, with a mean score of 19 at baseline, can be classified as marginally below average (range 15-19) at the start of the study, indicating small but significant problems in several areas of life or one area that represents a substantial problem (Pavot et al., 1991). During the sub-acute and follow-up assessments, participants' scores increased up to average (range 20-24) and marginally high (range 25-29) levels of SWL, respectively. Although people with average and high SWL are generally satisfied with their lives, the individuals with average scores desire greater improvements in one or several life's domains (Pavot et al., 1991). These findings are consistent with the previous studies showing sub-acute (Uthaug et al., 2018; Mason et al., 2019), and long-term (Bouso et al., 2012; Carhart-Harris et al., 2016; Griffiths et al., 2016; Johnson et al., 2017) positive psychological changes after psychedelics use. These findings add to the growing number of empirical evidence indicating that beneficial subjective psychological changes induced by psychedelics outlast the state of acute effects that in case of ayahuasca, last for approximately $4 \mathrm{~h}$ (Riba et al., 2001).
Although some of the ayahuasca compounds (e.g., THH) were demonstrated to have a half-life of almost $9 \mathrm{~h}$ (Callaway et al., 1999), studies employing a combination of electroencephalogram (EEG) recordings and quantification of ayahuasca's compounds concluded that it seems unlikely that those compounds play any major role in the acute psychoactive effects of ayahuasca (Schenberg et al., 2015).

As hypothesized, the study found decreases in neuroticism 1 week after the ayahuasca ceremony; the other four traits were unaffected. The fact that personality can change after a psychedelic experience has been shown previously (Griffiths et al., 2011; MacLean et al., 2011; Bouso et al., 2015; Johnstad 2021), however, most of the studies showed changes in openness which were not found in the present study. Previously it has been suggested that neuroticism could lead to difficult experiences when taking a psychedelic (Barrett et al., 2017), though other studies did not show this relation (Studerus et al., 2012; Haijen et al., 2018). Of interest here is that a previous study showed that individuals with low psychological well-being and higher scores of neuroticism report consuming psychedelic substances with the achievement of positive outcomes (Mason et al., 2020). Therefore, psychedelic-related changes in personality traits should be further investigated, to understand how personality changes over time and how this might facilitate the therapeutic process.

In the current study, we also found significant increases in ratings of decentering, both $24 \mathrm{~h}$ and 7 days after ingestion of ayahuasca. Findings are in line with previous studies, which havefound increases in decentering ability and interrelated mindfulness capacities $24 \mathrm{~h}$ (Soler et al., 2016; Uthaug et al., 2018; Murphy-Beiner and Soar 2020), 15 days (González et al., 2020), and 2 months (Sampedro et al., 2017) post ayahuasca intake. Decentering is described as the ability to take an observer's perspective on thoughts and emotions (Travers-Hill et al., 2017; Duncan et al., 2021), and is proposed to consist of three processes: meta-awareness, or the explicit awareness of the content of current consciousness, self-distancing from internal experiences (Kross et al., 2005), and reduced reactivity to thought content (Bernstein et al., 2015). Interestingly, previous work has found that when individuals are directed to analyze their feelings about negative autobiographical experiences from a self-distanced, decentered perspective (i.e. visualizing events from the perspective of an observer) versus a self-immersed, firstperson perspective, they demonstrate less acute emotional and physiological reactivity, and are less likely to ruminate over time (Kross et al., 2005; Kross and Ayduk 2008). Drawing from this distinction, Ayduk \& Kross (2010) have hypothesized that adopting and maintaining a self-distanced perspective while reflecting on emotions allows individuals to reconstruct their feelings and the meaning of their experience in ways that promote insight. This is interesting to think of in light of what individuals report during a psychedelic experience. Namely, individuals report reliving autobiographical memories, often viewed from a distanced, more detached view (Riba et al., 2001; Shanon, 2002; Riba et al., 2006), and subsequently report insights into their problems (Studerus et al., 2010; Roseman et al., 2018; GarciaRomeu et al., 2019). Given the similarity of these reports, and the finding of enhanced decentering abilities after a psychedelic, the 
concept of decentering is something that should be investigated more in the framework of psychedelic therapy, as this ability has been suggested to facilitate adaptive coping with depression, stress, and anxiety (Teasdale et al., 2002; Bieling et al., 2012; Hoge et al., 2015; O’Toole et al., 2019; Duncan et al., 2021) and thus drug-induced enhancements of such may play a role in the long-term clinical outcomes being observed in psychedelic clinical trials.

\section{Limitations and Conclusion}

The strength of this study, being naturalistic, is also its greatest limitation. While the ecological validity is high, the sample is selfselected, and it suffers from typically high drop-out rates. However, given the accumulated evidence on the importance of set (mind state and expectations) and setting (physical and social environment) on the outcomes of experience (Frecska et al., 2016; Hartogsohn 2016; Lawn et al., 2018; Sapoznikow et al., 2019), it is important to have an ecologically valid environment with participants enrolling in research, not engaging to receive a reward but to contribute to science. That said, it could also be that highly motivated people with a positive attitude were attracted to participate, hence generalisation towards the general population is difficult for this type of studies. The absence of a control group or placebo makes it challenging to draw hard conclusions, although the fact that the majority of findings (cognitive empathy, satisfaction with life, decentering) were in line with previous studies, some of which were placebo-controlled, is reassuring that the findings might be related to the psychedelic ceremony rather than practice effects or increased familiarity with the test material. Despite the promising character of the present findings, the high heterogeneity of methodological approaches in the psychedelic field (such as the time of assessment, setting, type of the substance) and the sparse number of studies investigating the effects of ayahuasca, with empathy in particular, hampers the formation of comprehensive conclusions. Given that core features of mood disorders include repetitive and rigid patterns of negative and compulsive thoughts, together with social difficulties and impaired empathic abilities (Nietlisbach and Maercker, 2009; Aldao and Nolen-Hoeksema, 2010; Morrison et al., 2016; Santos et al., 2016), the further

\section{REFERENCES}

Aldao, A., and Nolen-Hoeksema, S. (2010). Specificity of Cognitive Emotion Regulation Strategies: a Transdiagnostic Examination. Behav. Res. Ther. 48 (10), 974-983. doi:10.1016/j.brat.2010.06.002

Ayduk, O., and Kross, E. (2010). From a Distance: Implications of Spontaneous Self-Distancing for Adaptive Self-Reflection. J. Pers Soc. Psychol. 98 (5), 809-829. doi:10.1037/a0019205

Barbanoj, M. J., Riba, J., Clos, S., Giménez, S., Grasa, E., and Romero, S. (2008). Daytime Ayahuasca Administration Modulates REM and Slow-Wave Sleep in Healthy Volunteers. Psychopharmacology (Berl) 196 (2), 315-326. doi:10.1007/ s00213-007-0963-0

Barbosa, P. C., Giglio, J. S., and Dalgalarrondo, P. (2005). Altered States of Consciousness and Short-Term Psychological After-Effects Induced by the First Time Ritual Use of Ayahuasca in an Urban Context in Brazil. J. Psychoactive Drugs 37 (Issue 2), 193-201. doi:10.1080/02791072.2005.10399801 investigation of the preliminary benefits reported by the current and previous findings is of major importance. For instance, future placebo-controlled experimental studies could investigate potential non-pharmacological influences, while future longitudinal naturalistic research could further investigate the therapeutic potential of psychedelic drugs.

\section{DATA AVAILABILITY STATEMENT}

The original contributions presented in the study are included in the article/Supplementary Material, further inquiries can be directed to the corresponding author.

\section{ETHICS STATEMENT}

The studies involving human participants were reviewed and approved by Ethics Review Committee of Psychology and Neuroscience, Maastricht University, Faculty of Psychology and Neuroscience, Maastricht, the Netherlands. The patients/ participants provided their written informed consent to participate in this study.

\section{AUTHOR CONTRIBUTIONS}

NM, MK, JR, and KK conceived of the presented idea. NM, MU, and $\mathrm{KO}$ collected the data, MK and NM conducted the statistical analyses, SWT determined the concentrations of the ayahuasca components, MK, NM and KK prepared the first draft of the manuscript, and all authors discussed the results and contributed to the final manuscript.

\section{ACKNOWLEDGMENTS}

We would like to thank the ceremony organizers for allowing us to collect data at their ceremonies, and all participants for their time and effort.

Barrett, F. S., Johnson, M. W., and Griffiths, R. R. (2017). Neuroticism Is Associated with Challenging Experiences with Psilocybin Mushrooms. Pers Individ Dif 117, 155-160. doi:10.1016/j.paid.2017.06.004

Bedi, G., Hyman, D., and de Wit, H. (2010). Is Ecstasy an "empathogen"? Effects of $\pm 3,4$-methylenedioxymethamphetamine on Prosocial Feelings and Identification of Emotional States in Others. Biol. Psychiatry 68 (12), 1134-1140. doi:10.1016/j.biopsych.2010.08.003

Bernstein, A., Hadash, Y., Lichtash, Y., Tanay, G., Shepherd, K., and Fresco, D. M. (2015). Decentering and Related Constructs. Perspect. Psychol. Sci. 10 (5), 599-617. doi:10.1177/1745691615594577

Bieling, P. J., Hawley, L. L., Bloch, R. T., Corcoran, K. M., Levitan, R. D., Young, L. T., et al. (2012). Treatment-specific Changes in Decentering Following Mindfulness-Based Cognitive Therapy versus Antidepressant Medication or Placebo for Prevention of Depressive Relapse. J. Consult Clin. Psychol. 80 (3), 365-372. doi:10.1037/a0027483

Bouso, J. C., González, D., Fondevila, S., Cutchet, M., Fernández, X., Ribeiro Barbosa, P. C., et al. (2012). Personality, Psychopathology, Life Attitudes and 
Neuropsychological Performance Among Ritual Users of Ayahuasca: a Longitudinal Study. PLoS One 7 (8), e42421. doi:10.1371/journal.pone.0042421

Bouso, J. C., Palhano-Fontes, F., Rodríguez-Fornells, A., Ribeiro, S., Sanches, R., Crippa, J. A., et al. (2015). Long-term Use of Psychedelic Drugs Is Associated with Differences in Brain Structure and Personality in Humans. Eur. Neuropsychopharmacol. 25 (4), 483-492. doi:10.1016/j.euroneuro.2015.01.008

Callaway, J. C., McKenna, D. J., Grob, C. S., Brito, G. S., Raymon, L. P., Poland, R. E., et al. (1999). Pharmacokinetics of Hoasca Alkaloids in Healthy Humans. J. Ethnopharmacol 65 (3), 243-256. doi:10.1016/s0378-8741(98)00168-8

Carhart-Harris, R. L., Bolstridge, M., Rucker, J., Day, C. M., Erritzoe, D., Kaelen, M., et al. (2016). Psilocybin with Psychological Support for Treatment-Resistant Depression: an Open-Label Feasibility Study. Lancet Psychiatry 3 (7), 619-627. doi:10.1016/s2215-0366(16)30065-7

Carhart-Harris, R. L., Erritzoe, D., Williams, T., Stone, J. M., Reed, L. J., Colasanti, A., et al. (2012). Neural Correlates of the Psychedelic State as Determined by fMRI Studies with Psilocybin. Proc. Natl. Acad. Sci. U S A. 109 (6), 2138-2143. doi:10.1073/pnas.1119598109

Chamberlain, S. R., Fineberg, N. A., Blackwell, A. D., Robbins, T. W., and Sahakian, B. J. (2006). Motor Inhibition and Cognitive Flexibility in ObsessiveCompulsive Disorder and Trichotillomania. Am. J. Psychiatry 163 (7), 1282-1284. doi:10.1176/appi.ajp.163.7.1282

Cusi, A. M., Macqueen, G. M., Spreng, R. N., and McKinnon, M. C. (2011). Altered Empathic Responding in Major Depressive Disorder: Relation to Symptom Severity, Illness burden, and Psychosocial Outcome. Psychiatry Res. 188 (2), 231-236. doi:10.1016/j.psychres.2011.04.013

Da Silveira, D. X., Grob, C. S., de Rios, M. D., Lopez, E., Alonso, L. K., Tacla, C., et al. (2005). Ayahuasca in Adolescence: a Preliminary Psychiatric Assessment. J. Psychoactive Drugs 37 (2), 129-133. doi:10.1080/02791072.2005.10399792

de Lima Osório, F., de Macedo, L. R. H., de Sousa, J. P. M., Pinto, J. P., Quevedo, J., de Souza Crippa, J. A., et al. (2011). The Therapeutic Potential of Harmine and Ayahuasca in Depression: Evidence from Exploratory Animal and Human Studies. The Ethnopharmacology of Ayahuasca 75, 85.

Diener, E., Emmons, R. A., Larsen, R. J., and Griffin, S. (1985). The Satisfaction with Life Scale. J. Pers Assess. 49 (Issue 1), 71-75. doi:10.1207/ s15327752jpa4901_13

Dolder, P. C., Schmid, Y., Müller, F., Borgwardt, S., and Liechti, M. E. (2016). LSD Acutely Impairs Fear Recognition and Enhances Emotional Empathy and Sociality. Neuropsychopharmacology 41 (11), 2638-2646. doi:10.1038/ npp. 2016.82

Domínguez-Clavé, E., Soler, J., Pascual, J. C., Elices, M., Franquesa, A., Valle, M., et al. (2019). Ayahuasca Improves Emotion Dysregulation in a Community Sample and in Individuals with Borderline-like Traits. Psychopharmacology (Berl) 236 (2), 573-580. doi:10.1007/s00213-018-5085-3

Donges, U. S., Kersting, A., Dannlowski, U., Lalee-Mentzel, J., Arolt, V., and Suslow, T. (2005). Reduced Awareness of Others' Emotions in Unipolar Depressed Patients. J. Nerv Ment. Dis. 193 (5), 331-337. doi:10.1097/ 01.nmd.0000161683.02482.19

dos Santos, R. G., Osório, F. L., Crippa, J. A. S., Riba, J., Zuardi, A. W., Hallak, J. E. C., et al. (2016). Antidepressive, Anxiolytic, and Antiaddictive Effects of Ayahuasca, Psilocybin and Lysergic Acid Diethylamide (LSD): a Systematic Review of Clinical Trials Published in the Last 25 Years. Ther. Adv. Psychopharmacol. 6 (3), 193-213. doi:10.1177/2045125316638008

Duncan, N. S., Zimmer-Gembeck, M. J., Gardner, A. A., and Modecki, K. (2021). The Measurement and Benefit of Decentering for Coping Self-Efficacy, Flexibility, and Ways of Coping with Interpersonal Stress. Personal. Individual Differences 179, 110932. doi:10.1016/j.paid.2021.110932

Dziobek, I., Rogers, K., Fleck, S., Bahnemann, M., Heekeren, H. R., Wolf, O. T., et al. (2008). Dissociation of Cognitive and Emotional Empathy in Adults with Asperger Syndrome Using the Multifaceted Empathy Test (MET). J. Autism Dev. Disord. 38 (3), 464-473. doi:10.1007/s10803-007-0486-x

Erritzoe, D., Roseman, L., Nour, M. M., MacLean, K., Kaelen, M., Nutt, D. J., et al. (2018). Effects of Psilocybin Therapy on Personality Structure. Acta Psychiatr. Scand. 138 (5), 368-378. doi:10.1111/acps.12904

Frecska, E., Bokor, P., and Winkelman, M. (2016). The Therapeutic Potentials of Ayahuasca: Possible Effects against Various Diseases of Civilization. Front. Pharmacol. 7, 35. doi:10.3389/fphar.2016.00035

Frecska, E., Móré, C. E., Vargha, A., and Luna, L. E. (2012). Enhancement of Creative Expression and Entoptic Phenomena as After-Effects of Repeated
Ayahuasca Ceremonies. J. Psychoactive Drugs 44 (3), 191-199. doi:10.1080/ 02791072.2012 .703099

Fresco, D. M., Moore, M. T., van Dulmen, M. H., Segal, Z. V., Ma, S. H., Teasdale, J. D., et al. (2007). Initial Psychometric Properties of the Experiences Questionnaire: Validation of a Self-Report Measure of Decentering. Behav. Ther. 38 (3), 234-246. doi:10.1016/j.beth.2006.08.003

Garcia-Romeu, A., Davis, A. K., Erowid, F., Erowid, E., Griffiths, R. R., and Johnson, M. W. (2019). Cessation and Reduction in Alcohol Consumption and Misuse after Psychedelic Use. J. Psychopharmacol. 33 (9), 1088-1101. doi:10.1177/0269881119845793

González, D., Cantillo, J., Pérez, I., Farré, M., Feilding, A., Obiols, J. E., et al. (2020). Therapeutic Potential of Ayahuasca in Grief: a Prospective, Observational Study. Psychopharmacology (Berl) 237 (4), 1171-1182. doi:10.1007/s00213-019-05446-2

Griffiths, R. R., Johnson, M. W., Carducci, M. A., Umbricht, A., Richards, W. A., Richards, B. D., et al. (2016). Psilocybin Produces Substantial and Sustained Decreases in Depression and Anxiety in Patients with Life-Threatening Cancer: A Randomized Double-Blind Trial. J. Psychopharmacol. 30 (12), 1181-1197. doi:10.1177/0269881116675513

Griffiths, R. R., Johnson, M. W., Richards, W. A., Richards, B. D., McCann, U., and Jesse, R. (2011). Psilocybin Occasioned Mystical-type Experiences: Immediate and Persisting Dose-Related Effects. Psychopharmacology (Berl) 218 (4), 649-665. doi:10.1007/s00213-011-2358-5

Griffiths, R. R., Richards, W. A., McCann, U., and Jesse, R. (2006). Psilocybin Can Occasion Mystical-type Experiences Having Substantial and Sustained Personal Meaning and Spiritual Significance. Psychopharmacology (Berl) 187 (3), 268-292. doi:10.1007/s00213-006-0457-5

Haijen, E. C. H. M., Kaelen, M., Roseman, L., Timmermann, C., Kettner, H., Russ, S., et al. (2018). Predicting Responses to Psychedelics: A Prospective Study. Front. Pharmacol. 9. doi:10.3389/fphar.2018.00897

Hartogsohn, I. (2016). Set and Setting, Psychedelics and the Placebo Response: An Extra-pharmacological Perspective on Psychopharmacology. J. Psychopharmacol. 30 (12), 1259-1267. doi:10.1177/0269881116677852

Hoge, E. A., Bui, E., Goetter, E., Robinaugh, D. J., Ojserkis, R. A., Fresco, D. M., et al. (2015). Change in Decentering Mediates Improvement in Anxiety in Mindfulness-Based Stress Reduction for Generalized Anxiety Disorder. Cogn. Ther. Res. 39 (Issue 2), 228-235. doi:10.1007/s10608-014-9646-4

Hysek, C. M., Simmler, L. D., Schillinger, N., Meyer, N., Schmid, Y., Donzelli, M., et al. (2014). Pharmacokinetic and Pharmacodynamic Effects of Methylphenidate and MDMA Administered Alone or in Combination. Int. J. Neuropsychopharmacol. 17 (3), 371-381. doi:10.1017/ S1461145713001132

John, O. P., Donahue, E. M., and Kentle, R. L. (1991). The Big Five Inventory Versions $4 a$ and 54. Berkeley: University of California, Institute of Personality and Social Research.

John, O. P., and Srivastava, S. (1999). "The Big-Five Trait Taxonomy: History, Measurement, and Theoretical Perspectives," Handbook of Personality: Theory and Research. Editors L. A. Pervin and O. P. John, (New York: Guilford Press) Vol. 2, 102-138.

Johnson, M. W., Garcia-Romeu, A., and Griffiths, R. R. (2017). Long-term FollowUp of Psilocybin-Facilitated Smoking Cessation. Am. J. Drug Alcohol. Abuse 43 (Issue 1), 55-60. doi:10.3109/00952990.2016.1170135

Johnstad, P. G. (2021). The Psychedelic Personality: Personality Structure and Associations in a Sample of Psychedelics Users. J. Psychoactive Drugs 53 (2), 97-103. doi:10.1080/02791072.2020.1842569

Kometer, M., Schmidt, A., Bachmann, R., Studerus, E., Seifritz, E., and Vollenweider, F. X. (2012). Psilocybin Biases Facial Recognition, GoalDirected Behavior, and Mood State toward Positive Relative to Negative Emotions through Different Serotonergic Subreceptors. Biol. Psychiatry 72 (11), 898-906. doi:10.1016/j.biopsych.2012.04.005

Kross, E., and Ayduk, O. (2008). Facilitating Adaptive Emotional Analysis: Distinguishing Distanced-Analysis of Depressive Experiences from Immersed-Analysis and Distraction. Pers Soc. Psychol. Bull. 34 (7), 924-938. doi:10.1177/0146167208315938

Kross, E., Ayduk, O., and Mischel, W. (2005). When Asking "why" Does Not Hurt. Distinguishing Rumination from Reflective Processing of Negative Emotions. Psychol. Sci. 16 (9), 709-715. doi:10.1111/j.1467-9280.2005.01600.x

Kuypers, K. P., Riba, J., de la Fuente Revenga, M., Barker, S., Theunissen, E. L., and Ramaekers, J. G. (2016). Ayahuasca Enhances Creative Divergent Thinking 
while Decreasing Conventional Convergent Thinking. Psychopharmacology (Berl) 233 (18), 3395-3403. doi:10.1007/s00213-016-4377-8

Kuypers, K. P. C., Dolder, P. C., Ramaekers, J. G., and Liechti, M. E. (2017). Multifaceted Empathy of Healthy Volunteers after Single Doses of MDMA: A Pooled Sample of Placebo-Controlled Studies. J. Psychopharmacol. 31 (5), 589-598. doi:10.1177/0269881117699617

Kuypers, K. P. C. (2018). Out of the Box: A Psychedelic Model to Study the Creative Mind. Med. Hypotheses 115, 13-16. doi:10.1016/j.mehy.2018.03.010

Lawn, W., Hallak, J. E., Crippa, J. A., Dos Santos, R., Porffy, L., Barratt, M. J., et al. (2018). Author Correction: Well-Being, Problematic Alcohol Consumption and Acute Subjective Drug Effects in Past-Year Ayahuasca Users: a Large, International, Self-Selecting Online Survey. Sci. Rep. 8 (1), 4059. doi:10.1038/s41598-018-21666-6

Leary, M. R. (2014). Introduction to Behavioral Research Methods, Vol. 6. Pearson Education Limited.

Lee, J. K., and Orsillo, S. M. (2014). Investigating Cognitive Flexibility as a Potential Mechanism of Mindfulness in Generalized Anxiety Disorder. J. Behav. Ther. Exp. Psychiatry 45 (1), 208-216. doi:10.1016/j.jbtep.2013.10.008

MacLean, K. A., Johnson, M. W., and Griffiths, R. R. (2011). Mystical Experiences Occasioned by the Hallucinogen Psilocybin lead to Increases in the Personality Domain of Openness. J. Psychopharmacol. 25 (11), 1453-1461. doi:10.1177/ 0269881111420188

Mason, N. L., Kuypers, K. P. C., Reckweg, J. T., Müller, F., Tse, D. H. Y., Da Rios, B., et al. (2021). Spontaneous and Deliberate Creative Cognition during and after Psilocybin Exposure. Transl Psychiatry 11 (1), 209. doi:10.1038/s41398-02101335-5

Mason, N. L., Mischler, E., Uthaug, M. V., and Kuypers, K. P. C. (2019). Sub-Acute Effects of Psilocybin on Empathy, Creative Thinking, and Subjective WellBeing. J. Psychoactive Drugs 51 (2), 123-134. doi:10.1080/ 02791072.2019.1580804

Mason, N. L., Dolder, P. C., and Kuypers, K. P. (2020). Reported Effects of Psychedelic Use on Those with Low Well-Being Given Various Emotional States and Social Contexts. Drug Sci. Pol. L. 6, 205032451990006. doi:10.1177/ 2050324519900068

Mason, N. L., and Kuypers, K. P. C. (2021). "Acute and Long-Term Effects of Ayahuasca on (Higher-Order) Cognitive Processes," in Ayahuasca Healing and Science. Editors B. C. Labate and C. Cavnar (Springer Nature), 117-136. doi:10.1007/978-3-030-55688-4_7

Morrison, A. S., Mateen, M. A., Brozovich, F. A., Zaki, J., Goldin, P. R., Heimberg, R. G., et al. (2016). Empathy for Positive and Negative Emotions in Social Anxiety Disorder. Behav. Res. Ther. 87, 232-242. doi:10.1016/j.brat.2016.10.005

Murphy-Beiner, A., and Soar, K. (2020). Ayahuasca's 'afterglow': Improved Mindfulness and Cognitive Flexibility in Ayahuasca Drinkers. Psychopharmacology (Berl) 237 (4), 1161-1169. doi:10.1007/s00213-01905445-3

Nietlisbach, G., and Maercker, A. (2009). Social Cognition and Interpersonal Impairments in Trauma Survivors with PTSD. J. Aggression, Maltreat. Trauma 18 (4), 382-402. doi:10.1080/10926770902881489

Nour, M. M., Evans, L., and Carhart-Harris, R. L. (2017). Psychedelics, Personality and Political Perspectives. J. Psychoactive Drugs 49 (3), 182-191. doi:10.1080/ 02791072.2017.1312643

Nour, M. M., Evans, L., Nutt, D., and Carhart-Harris, R. L. (2016). Ego-Dissolution and Psychedelics: Validation of the Ego-Dissolution Inventory (EDI). Front. Hum. Neurosci. 10, 269. doi:10.3389/fnhum.2016.00269

O'Toole, M. S., Renna, M. E., Mennin, D. S., and Fresco, D. M. (2019). Changes in Decentering and Reappraisal Temporally Precede Symptom Reduction during Emotion Regulation Therapy for Generalized Anxiety Disorder with and without Co-occurring Depression. Behav. Ther. 50 (6), 1042-1052. doi:10.1016/j.beth.2018.12.005

Palhano-Fontes, F., Andrade, K. C., Tofoli, L. F., Santos, A. C., Crippa, J. A., Hallak, J. E., et al. (2015). The Psychedelic State Induced by Ayahuasca Modulates the Activity and Connectivity of the Default Mode Network. PLOS ONE 10 (2), e0118143. doi:10.1371/journal.pone.0118143

Palhano-Fontes, F., Barreto, D., Onias, H., Andrade, K. C., Novaes, M. M., Pessoa, J. A., et al. (2019). Rapid Antidepressant Effects of the Psychedelic Ayahuasca in Treatment-Resistant Depression: a Randomized PlaceboControlled Trial. Psychol. Med. 49 (4), 655-663. doi:10.1017/ S0033291718001356
Palhano-Fontes, F., Mota-Rolim, S., Lobão-Soares, B., Galvão-Coelho, N., MaiaOliveira, J. P., and Araújo, D. B. (2021). Recent Evidence on the Antidepressant Effects of Ayahuasca. Ayahuasca Healing Sci. 21. doi:10.1007/978-3-03055688-4_2

Palm, K. M., and Follette, V. M. (2011). The Roles of Cognitive Flexibility and Experiential Avoidance in Explaining Psychological Distress in Survivors of Interpersonal Victimization. J. Psychopathol Behav. Assess. 33 (1), 79-86. doi:10.1007/s10862-010-9201-x

Parlar, M., Frewen, P., Nazarov, A., Oremus, C., MacQueen, G., Lanius, R., et al. (2014). Alterations in Empathic Responding Among Women with Posttraumatic Stress Disorder Associated with Childhood Trauma. Brain Behav. 4 (3), 381-389. doi:10.1002/brb3.215

Pavot, W., Diener, E., Colvin, C. R., and Sandvik, E. (1991). Further Validation of the Satisfaction with Life Scale: Evidence for the Cross-Method Convergence of Well-Being Measures. J. Pers Assess. 57 (1), 149-161. doi:10.1207/ s15327752jpa5701_17

Pokorny, T., Preller, K. H., Kometer, M., Dziobek, I., and Vollenweider, F. X. (2017). Effect of Psilocybin on Empathy and Moral Decision-Making. Int. J. Neuropsychopharmacol. 20 (9), 747-757. doi:10.1093/ijnp/pyx047

Preller, K. H., Pokorny, T., Krähenmann, R., Dziobek, I., Stämpfli, P., and Vollenweider, F. X. (2015). The Effect of 5-HT2A/1a Agonist Treatment on Social Cognition, Empathy, and Social Decision-Making. Eur. Psychiatry J. Assoc. Eur. Psychiatrists 30 (S1), 1. doi:10.1016/S0924-9338(15)30017-1

Riba, J., Rodríguez-Fornells, A., Urbano, G., Morte, A., Antonijoan, R., Montero, M., et al. (2001). Subjective Effects and Tolerability of the South American Psychoactive Beverage Ayahuasca in Healthy Volunteers. Psychopharmacology (Berl) 154 (1), 85-95. doi:10.1007/s002130000606

Riba, J., Romero, S., Grasa, E., Mena, E., Carrió, I., and Barbanoj, M. J. (2006). Increased Frontal and Paralimbic Activation Following Ayahuasca, the PanAmazonian Inebriant. Psychopharmacology (Berl) 186 (1), 93-98. doi:10.1007/ s00213-006-0358-7

Riba, J., Valle, M., Urbano, G., Yritia, M., Morte, A., and Barbanoj, M. J. (2003). Human Pharmacology of Ayahuasca: Subjective and Cardiovascular Effects, Monoamine Metabolite Excretion, and Pharmacokinetics. J. Pharmacol. Exp. Ther. 306 (1), 73-83. doi:10.1124/jpet.103.049882

Roseman, L., Nutt, D. J., and Carhart-Harris, R. L. (2018). Quality of Acute Psychedelic Experience Predicts Therapeutic Efficacy of Psilocybin for Treatment-Resistant Depression. Front. Pharmacol. 8. doi:10.3389/ fphar.2017.00974

Sampedro, F., de la Fuente Revenga, M., Valle, M., Roberto, N., Domínguez-Clavé, E., Elices, M., et al. (2017). Assessing the Psychedelic "After-Glow" in Ayahuasca Users: Post-Acute Neurometabolic and Functional Connectivity Changes Are Associated with Enhanced Mindfulness Capacities. Int. J. Neuropsychopharmacol. 20 (9), 698-711. doi:10.1093/ijnp/pyx036

Sanches, R. F., de Lima Osório, F., dos Santos, R. G., Macedo, L. R., Maia-deOliveira, J. P., Wichert-Ana, L., et al. (2016). Antidepressant Effects of a Single Dose of Ayahuasca in Patients with Recurrent Depression: A SPECT Study. J. Clin. Psychopharmacol. 36 (1), 77-81. doi:10.1097/jcp.0000000000000436

Sapoznikow, A., Walsh, Z., Tupper, K. W., Erowid, E., and Erowid, F. (2019). The Influence of Context on Ayahuasca Experiences: An Analysis of Experience Reports. J. Psychedelic Stud. 3 (3), 288-294. doi:10.1556/2054.2019.028

Sarris, J., Perkins, D., Cribb, L., Schubert, V., Opaleye, E., Bouso, J. C., et al. (2021). Ayahuasca Use and Reported Effects on Depression and Anxiety Symptoms: An International Cross-Sectional Study of 11,912 Consumers. J. Affective Disord. Rep. 4, 100098. doi:10.1016/j.jadr.2021.100098

Schenberg, E. E., Alexandre, J. F., Filev, R., Cravo, A. M., Sato, J. R., Muthukumaraswamy, S. D., et al. (2015). Acute Biphasic Effects of Ayahuasca. PLoS One 10 (9), e0137202. doi:10.1371/journal.pone.0137202

Schmid, J. T. (2012). The Myth of Ayahuasca. TYPES, EFFICACY AND MYTHS 127. https://www.academia.edu/download/36512865/978-1-61470-657-1_ eBook_NOVA.pdf\#page $=139$.

Schmid, Y., Hysek, C. M., Simmler, L. D., Crockett, M. J., Quednow, B. B., and Liechti, M. E. (2014). Differential Effects of MDMA and Methylphenidate on Social Cognition. J. Psychopharmacol. 28 (9), 847-856. doi:10.1177/ 0269881114542454

Schmid, Y., and Liechti, M. E. (2018). Long-lasting Subjective Effects of LSD in normal Subjects. Psychopharmacology (Berl) 235 (2), 535-545. doi:10.1007/ s00213-017-4733-3 
Schultes, R. E. (1986). Recognition of Variability in Wild Plants by Indians of the Northwest Amazon: An enigma. J. Ethnobiol. 6 (2). Available at: https:// ethnobiology.org/sites/default/files/pdfs/JoE/6-2/Schultes1986.pdf.

Shanon, B. (2002). The Antipodes of the Mind: Charting the Phenomenology of the Ayahuasca Experience. Oxford University Press. https://play.google.com/store/ books/details?id=rIhdbLq-Mc0C.

Soler, J., Elices, M., Franquesa, A., Barker, S., Friedlander, P., Feilding, A., et al. (2016). Exploring the Therapeutic Potential of Ayahuasca: Acute Intake Increases Mindfulness-Related Capacities. Psychopharmacology (Berl) 233 (5), 823-829. doi:10.1007/s00213-015-4162-0

Soler, J., Franquesa, A., Feliu-Soler, A., Cebolla, A., García-Campayo, J., Tejedor, R., et al. (2014). Assessing Decentering: Validation, Psychometric Properties, and Clinical Usefulness of the Experiences Questionnaire in a Spanish Sample. Behav. Ther. 45 (6), 863-871. doi:10.1016/j.beth.2014.05.004

Studerus, E., Gamma, A., Kometer, M., and Vollenweider, F. X. (2012). Prediction of Psilocybin Response in Healthy Volunteers. PLoS One 7 (2), e30800. doi:10.1371/journal.pone.0030800

Studerus, E., Gamma, A., and Vollenweider, F. X. (2010). Psychometric Evaluation of the Altered States of Consciousness Rating Scale (OAV). PLoS ONE 5 (8), e12412. doi:10.1371/journal.pone.0012412

Teasdale, J. D., Moore, R. G., Hayhurst, H., Pope, M., Williams, S., and Segal, Z. V. (2002). Metacognitive Awareness and Prevention of Relapse in Depression: Empirical Evidence. J. Consult Clin. Psychol. 70 (2), 275-287. doi:10.1037/0022-006x.70.2.275

Travers-Hill, E., Dunn, B. D., Hoppitt, L., Hitchcock, C., and Dalgleish, T. (2017). Beneficial Effects of Training in Self-Distancing and Perspective Broadening for People with a History of Recurrent Depression. Behav. Res. Ther. 95, 19-28. doi:10.1016/j.brat.2017.05.008

Tull, M. T., and Roemer, L. (2007). Emotion Regulation Difficulties Associated with the Experience of Uncued Panic Attacks: Evidence of Experiential Avoidance, Emotional Nonacceptance, and Decreased Emotional Clarity. Behav. Ther. 38 (4), 378-391. doi:10.1016/j.beth.2006.10.006

Tupper, K. W. (2008). The Globalization of Ayahuasca: Harm Reduction or Benefit Maximization. Int. J. Drug Pol. 19 (4), 297-303. doi:10.1016/j.drugpo.2006.11.001

Uthaug, M. V., Lancelotta, R., van Oorsouw, K., Kuypers, K. P. C., Mason, N., Rak, J., et al. (2019). A Single Inhalation of Vapor from Dried Toad Secretion Containing 5-Methoxy-N,N-Dimethyltryptamine (5-MeO-DMT) in a Naturalistic Setting Is Related to Sustained Enhancement of Satisfaction with Life, Mindfulness-Related Capacities, and a Decrement of Psychopathological Symptoms. Psychopharmacology (Berl) 236 (9), 2653-2666. doi:10.1007/s00213-019-05236-w
Uthaug, M. V., van Oorsouw, K., Kuypers, K. P. C., van Boxtel, M., Broers, N. J., Mason, N. L., et al. (2018). Sub-acute and Long-Term Effects of Ayahuasca on Affect and Cognitive Thinking Style and Their Association with Ego Dissolution. Psychopharmacology (Berl) 235 (10), 2979-2989. doi:10.1007/ s00213-018-4988-3

Uthaug, M. V., Mason, N. L., Toennes, S. W., Reckweg, J. T., de Sousa Fernandes Perna, E. B., Kuypers, K. P. C., et al. (2021). A Placebo-Controlled Study of the Effects of Ayahuasca, Set and Setting on Mental Health of Participants in Ayahuasca Group Retreats. Psychopharmacology 238, 1899-1910. doi:10.1007/ s00213-021-05817-8

Valle, M., Maqueda, A. E., Rabella, M., Rodríguez-Pujadas, A., Antonijoan, R. M., Romero, S., et al. (2016). Inhibition of Alpha Oscillations through serotonin-2A Receptor Activation Underlies the Visual Effects of Ayahuasca in Humans. Eur. Neuropsychopharmacol. $26 \quad$ (7), 1161-1175. doi:10.1016/ j.euroneuro.2016.03.012

van Oorsouw, K. I., Uthaug, M. V., Mason, N. L., Broers, N. J., and Ramaekers, J. G. (2021). Sub-acute and Long-Term Effects of Ayahuasca on Mental Health and Well-Being in Healthy Ceremony Attendants: A Replication Study. J. Psychedelic Stud. doi:10.1556/2054.2021.00174

Winkelman, M. (2005). Drug Tourism or Spiritual Healing? Ayahuasca Seekers in Amazonia. J. Psychoactive Drugs 37 (2), 209-218. doi:10.1080/ 02791072.2005.10399803

Conflict of Interest: The authors declare that the research was conducted in the absence of any commercial or financial relationships that could be construed as a potential conflict of interest.

Publisher's Note: All claims expressed in this article are solely those of the authors and do not necessarily represent those of their affiliated organizations, or those of the publisher, the editors and the reviewers. Any product that may be evaluated in this article, or claim that may be made by its manufacturer, is not guaranteed or endorsed by the publisher.

Copyright (C) 2021 Kiraga, Mason, Uthaug, van Oorsouw, Toennes, Ramaekers and Kuypers. This is an open-access article distributed under the terms of the Creative Commons Attribution License (CC BY). The use, distribution or reproduction in other forums is permitted, provided the original author(s) and the copyright owner(s) are credited and that the original publication in this journal is cited, in accordance with accepted academic practice. No use, distribution or reproduction is permitted which does not comply with these terms. 